\title{
Nutrition in Reproductive Health: Nutritional Conditioning Factors during Pregnancy and Its Impact on Health
}

\author{
Juan Miguel Martínez-Galiano ${ }^{1,2, *}$, Naomi Cano-Ibáñez ${ }^{2,3,4}$ (D) Antonio Hernández-Martínez ${ }^{5}$ (D) \\ and Miguel Delgado-Rodríguez ${ }^{2,6}$ \\ 1 Department of Nursing, University of Jaen, 23071 Jaen, Spain \\ 2 Consortium for Biomedical Research in Epidemiology and Public Health (CIBERESP), 28029 Madrid, Spain; \\ ncaiba@ugr.es (N.C.-I.); mdelgado@ujaen.es (M.D.-R.) \\ 3 Department of Preventive Medicine and Public Health, University of Granada, 18011 Granada, Spain \\ 4 Biosanitary Research Institute Granada (ibs.GRANADA), 18012 Granada, Spain \\ 5 Department of Nursing, Faculty of Nursing of Ciudad Real, University of Castilla-La Mancha, \\ 13071 Ciudad Real, Spain; Antonio.HMartinez@uclm.es \\ 6 Department of Health Sciences, University of Jaen, 23071 Jaen, Spain \\ * Correspondence: jgaliano@ujaen.es; Tel.: +34-953211740
}

Received: 27 August 2020; Accepted: 12 October 2020; Published: 14 October 2020

\begin{abstract}
During the gestational period, women need to have optimal health to meet fetal requirements for growth and development. Nutrition is one of the most important factors that can ensure a mother's health and also that of their offspring. The role of maternal diet, before and during pregnancy, has been associated with adverse birth outcomes and a worsening of maternal health. Medical conditions that are closely related to dietary intake and may affect women before or during pregnancy have also been associated with the appearance of pathology in a newborn. To date, several studies have been carried out in order to identify the role of diet as a factor associated with child physiological and psychological health, both in the short and long term. Educating mothers regarding the influence of maternal dietary intake during pregnancy on infants' health could represent a simple but effective target for public health policies to improve pregnancy nutrition, and therefore help to avoid newborn diseases through the development.
\end{abstract}

Keywords: early programming factors; pregnancy; maternal diet; offspring

\section{Introduction}

A correct diet is essential in order to maintain an adequate nutritional status at all stages of life. During pregnancy, nutritional needs are increased in order to meet fetal requirements. Nutrition plays a fundamental role within the known concept of early programming factors, during both the gestational period and the preconception stage. For this reason, it is important to carry out a detailed analysis of lifestyle factors before a woman becomes pregnant in order to identify the factors that may influence her health and, either directly or indirectly, the health of her future baby. It is especially important, both before and during pregnancy, to conduct comprehensive health promotions which focus on the promotion of healthy lifestyles, empowering women to make the decisions needed for the acquisition of safe and healthy eating habits that guarantee a good health result, i.e., "a term pregnancy with the lowest physical risk and the highest quality of life possible for the pregnant woman and the birth of a healthy baby" [1].

In this article, we assess the influence of a mother's maternal diet and nutritional status, before and during pregnancy, on the appearance of several conditions in their fetus, newborn, and child. Given 
the importance of this, as recognized by clinical guidelines, the component of nutritional intervention has been incorporated as one of the aspects to be carried out during prenatal and preconception care counseling.

During the care provided to women through primary health care for preconception health, carried out in the year before becoming pregnant, different aspects must be addressed. This care, although it has common components, should be adapted to the reality and needs of each woman. Thus, emphasis should be placed on adopting healthy lifestyles where the basic premises are as follows: maintaining an active lifestyle with adequate physical activity, avoiding alcohol consumption, encouraging smoking cessation, and promoting a balanced diet, among others. Pre-existing conditions, social support available to an expectant mother, and exposure to environmental factors such as atmospheric pollutants (concentrations of polycyclic aromatic hydrocarbons, carbon monoxide, etc.) must be assessed and verified. All of these are risk factors for the baby's health [2].

Preparation is necessary before pregnancy, in addition to the care that is carried out during pregnancy. Adequate antenatal follow-up reduces maternal, fetal, neonatal, and infant morbidity and mortality, up to five years of age [3-6]. Despite the benefits that adequate prenatal care has shown, many women still do not consider their prenatal care. Multiple factors and determinants have been identified, including a low socioeconomic and cultural level, domestic abuse, and excessive burden of their duties within the family that hinder prenatal care attendance [7-9]. Health strategies and policies must implement measures to encourage women to have adequate follow-up after a pregnancy, to ensure good progress of a pregnancy, and to be able to detect any alteration to the normal course of early pregnancy, in order to establish appropriate socio-sanitary measures to minimize any impact on the health of a mother and fetus. This could reduce healthcare costs derived from maternal and child comorbidities and also increase the quality of life for a pregnant woman.

This prenatal care, including preconception care, is not standard for all women because it is not present in all healthcare systems worldwide. The type of follow-up depends on the health provider, the evolution of the pregnancy, and the sociodemographic characteristics of the woman. Antenatal care involves a series of periodic reviews that encompasses prevention, diagnosis, and treatment of those factors that can condition maternal and neonatal morbidity and mortality. There different guidelines in each country, and even within the same country. For example, in Spain, despite the existence of a practical care guide from the Spanish Society of Gynecology and Obstetrics (SEGO) [10], prenatal care varies among Spanish regions [11,12]. These guidelines are instruments that enable the monitoring to be carried out in a standardized way for each woman. The World Health Organization (WHO) has established several recommendations regarding routine prenatal care for all pregnant women. The purpose of this guide is to reflect and to answer the complex nature of the issues surrounding the practice of prenatal care. Furthermore, these guidelines are aimed at preventing the mortality and morbidity of a mother and fetus and prioritizing the well-being of a mother, in accordance with a human rights-based approach [13]. This guideline addresses various recommendations to be taken into account which include the following: nutritional interventions (food interventions, supplementation with micronutrients and vitamins); maternal evaluation (maternal anemia, asymptomatic bacteriuria, etc.); fetal evaluation (daily estimation of fetal movement, measurement of uterine height, etc.); precaution measures; and some interventions for common physiological symptoms such as leg cramps, nausea, vomiting, heartburn, low back pain, pelvic pain, constipation, varicose veins, and edema. Finally, these guidelines also contain information on specific interventions in health systems to improve the use and quality of prenatal care (perinatal card, midwifery continuity of care, etc.) [13].

\section{Nutritional Status of Pregnant Women}

The WHO defines nutritional status as the interpretation of information obtained from biochemical, anthropometric, and/or clinical studies used to determine the nutritional status of individuals or populations. Assessment of nutritional status is essential because it allows us to make a diagnosis and, if necessary, to propose treatment. The international approved measure is the body mass index (BMI) 
(weight divided by height in meters squared), or the Quetelet index, in reference to the statistician who developed it. For pregnant women, according to the National Academy of Sciences, BMI is classified as follows [14]:

* Low weight, BMI $<19.8 \mathrm{Kg} / \mathrm{m}^{2}$;

* Normal, BMI 19.8-26 Kg/m²;

* Overweight, BMI 26.1-29 Kg/m²;

* Obesity, BMI $>29 \mathrm{Kg} / \mathrm{m}^{2}$.

This BMI classification does not coincide with that of the WHO for the general adult population, although the differences between them are minimal. Thus, for example, the WHO cut-off point for overweight in the adult population is a BMI $\geq 25 \mathrm{Kg} / \mathrm{m}^{2}$ [15].

The pregnancy weight gain curve, called Rosso and Mardones, is another resource used in Latin America to guide weight gain during pregnancy. It was designed as an instrument to evaluate the relationship between weight and height at each gestational age based on the perinatal result. The weight/height ratio is expressed as the percentage of the ideal or standard weight according to the BMI. The ideal weight is derived from the adequacy of weight for height in the tables developed for this purpose. The Rosso and Mardones defines categories of maternal nutritional status according to the mother's weight and height [16].

The nutritional status of a pregnant woman measured through BMI has been associated with different adverse maternal and neonatal outcomes. Nevertheless, it is important to note that the nutritional state of a mother influences offspring results, even before a woman becomes pregnant. Therefore, it is convenient to monitor preconception nutritional status and carry out necessary interventions so that a woman begins a pregnancy with an adequate nutritional status, preventing the possible appearance of maternal and neonatal conditions from the beginning.

Weight gain during pregnancy is another measure considered for assessing the nutritional status of a pregnant woman. This is a measure to assess the well-being of a pregnant woman and the fetus. When weight gain is insufficient or excessive, it represents a significant risk of certain maternal and fetal diseases, both in the short, medium, and long term [17]. For a well-nourished woman, normal weight gain by late pregnancy ranges from approximately 11 to $16 \mathrm{~kg}$. Weight gain during pregnancy tends to be less, the higher the prepregnancy BMI, and also depends on whether it is a single or twin pregnancy. For a single gestation, the recommendations for weight gain, according to BMI, can be seen in Table 1 [10].

Table 1. Recommendations for weight gain during pregnancy, according to body mass index (BMI).

\begin{tabular}{ccc}
\hline BMI Classification & $\begin{array}{c}\text { Recommended Weight Gain for } \\
\text { Single Gestation }\end{array}$ & $\begin{array}{c}\text { Recommended Weight Gain for } \\
\text { Twin Pregnancy }\end{array}$ \\
\hline $\begin{array}{c}\text { With a normal weight } \\
\left(\text { BMI: } 18.5 \text { and } 24.9 \mathrm{~kg} / \mathrm{m}^{2}\right)\end{array}$ & Between 11.5 and $16 \mathrm{~kg}$ & Between 16.8 and $24.5 \mathrm{~kg}$ \\
\hline $\begin{array}{c}\text { Overweight } \\
\left(\text { BMI: } 25 \text { and } 29.9 \mathrm{~kg} / \mathrm{m}^{2}\right)\end{array}$ & Between 7 and $12.5 \mathrm{~kg}$ & Between 14.1 and $22.7 \mathrm{~kg}$ \\
\hline $\begin{array}{c}\text { With obesity } \\
\left(\mathrm{BMI} \geq 30 \mathrm{~kg} / \mathrm{m}^{2}\right)\end{array}$ & Between 5 and $9 \mathrm{~kg}$ & Between 11 and $19.1 \mathrm{~kg}$ \\
\hline
\end{tabular}

Dietary evaluation and nutritional education of a pregnant woman should be routine practices incorporated into obstetric clinics as tools to improve health during pregnancy and puerperium. Accordingly, it is essential to know the preconception weight and height and monitor the BMI/gestational age according to the curve at each scheduled consultation. Likewise, evaluation of dietary practices is highly advisable to detect harmful and inadvisable dietary habits that should be modified to improve the nutritional status of women and children [18]. 


\section{Effects of Nutritional Status of Pregnant Women on Maternal Morbidity}

During the course of a normal pregnancy, different diseases can appear and influence the normal development of pregnancy. Among these diseases, those noteworthy for their frequency and consequences include gestational diabetes, different hypertensive disorders (preeclampsia, hellp syndrome, etc.), premature rupture of membranes, maternal anemia, liver diseases (such as cholestasis gravidarum), and psychiatric disorders (such as depression and anxiety). These maternal diseases have repercussions on the health and well-being of a fetus, a newborn, and later a child at a physical and psychological level. Some of the offspring pathologies associated with the presence of maternal disease during pregnancy are the following: attention deficit hyperactivity disorder (ADHD); intrauterine growth retardation with several consequences for a baby's physical and psychological health in the short, medium, and long term; liver disease; bone marrow disorders; poor growth; and an increased risk of endocrine, nutritional, and metabolic disorders during adolescence and early adulthood [19-25].

The maternal nutritional status analyzed in terms of nutritional intake, taking into account a deficient or excessive intake of some nutrients, as well as a mother's dietary pattern, BMI, and pregnancy weight gain, has been associated with a higher incidence of diseases during pregnancy and a negative impact on a baby's health. Therefore, maternal diet, nutritional status, or weight gain during pregnancy have an indirect impact on the incidence of disease in babies through an increased risk of disease during pregnancy. Along these lines, the Mediterranean dietary pattern is associated with a lower incidence of gestational diabetes. Considering each of the food groups, a high intake of vegetables prevents the appearance of preeclampsia, and the intake of vegetables, fruits, nuts, legumes, fish and seafood, olive oil, and dairy products has a protective effect against depressive symptoms in pregnant women. As far as micronutrients are concerned, low consumption of nutrients rich in iron content is a risk factor for developing anemia in pregnancy, while a high weight gain during pregnancy represents a greater risk of pre-eclampsia [26-30]. Obesity is also associated with the type of delivery and is a risk factor for non-eutocic delivery with the consequences that this entails for a baby's health [31]. Poor maternal dietary habits contribute to micronutrient deficiencies, despite an increase in energy content. Hence, maternal dietary guidelines emphasize the importance of a varied, balanced, and moderated diet to reduce the risk of diet-related chronic diseases such as the dual burden of malnutrition during pregnancy.

\section{Effects of Nutritional Status of Pregnant Women on the Fetus, the Newborn, and the Child}

A fetus feeds and receives oxygen through the placenta. Accordingly, the placenta and its correct functioning play a fundamental role in the development of a fetus. Deficits or excess of specific nutrients in a mother have an impact on the fetus. Therefore, mothers need to maintain an adequate nutritional status before and during pregnancy. Some epidemiological studies have shown that poor vascular perfusion on the fetal side of the placenta (related to maternal pathology such as hypertension) is associated with an increased risk of neonatal encephalopathy or a higher incidence of small-for-gestational-age newborns [32,33].

The maternal diet and the nutritional status of a mother, both before and during pregnancy, will condition the state of health and the presence of disease in the fetus, during its intrauterine life and including into adulthood. Deficient nutrient intake during the prenatal stage can play an important role in the programming of multiple organ systems and could increase the general susceptibility to disease in the offspring [34]. There is a significant number of unintended pregnancies; therefore, women of reproductive age should maintain an adequate intake of nutrients and a correct nutritional status. Health professionals must influence the need for an adequate diet for the entire population, but with special emphasis on women of reproductive age.

Excess weight in a mother has been associated with a higher heart rate and less variability during the fetal stage. This has also been associated with the appearance of chronic diseases that begin in early childhood and that have serious consequences in adulthood such as childhood obesity, cancer, type 2 diabetes, increased cardiovascular risk, atypical neurological development, increased risk of psychiatric 
disorders (cognitive impairment, autism spectrum disorders, ADHD), cerebral palsy, anxiety and depression, schizophrenia, and eating disorders [35-42].

Insufficient weight gain during pregnancy, or a low BMI, has also been associated with an increased risk of perinatal death and severe neonatal morbidity [43]. For all these reasons, it is essential to highlight the importance for pregnant women to maintain an adequate nutritional status within the recommended parameters, avoiding not only excess but also deficient weight.

The most studied effects, in terms of their association with BMI or weight gain during pregnancy, are a small-for-gestational-age newborn, low birth weight newborn, and a preterm newborn. These three circumstances carry serious consequences for the health of a child in the short, medium, and long term, i.e., growth disorders, adrenarche, intellectual and neurological disorders (cognitive disorders, hyperactivity, lower professional level, etc.) and metabolic consequences [44-47]. Insufficient BMI, or weight gain of a mother during pregnancy, has been associated with a higher incidence of low birth weight newborns, i.e., weighing less than $2500 \mathrm{~g}$, or small for gestational age newborn, i.e., size, head circumference, or birth weight below the 10th percentile, and preterm birth, that is, before 37 weeks of gestation [48-51].

Poor quality of the periconceptional diet is associated with neonatal adverse outcomes such as premature delivery, admission to the neonatal intensive care unit, small for gestational age infants, and low birth weight [52].

During the course of pregnancy, women's dietary habits, dietary pattern, nutrient deficient intake, and supplement intake have also been associated with the risk of fetal, neonatal, and childhood diseases. Greater adherence to a dietary pattern of fast food and sweets before pregnancy increases the chances of birth of a large-for-gestational-age newborn, while greater adherence to vegetables and dairy decreases the chances of premature delivery [53]. A higher prevalence of maternal nutritional deficiencies, a lower dietary diversity score, and consumption of a smaller variety of dairy products, have been significantly associated with a lower risk of having a small-for-gestational-age newborn [54].

Many nutrients have been investigated and associated with different conditions in a baby. For example, adequate consumption of folates, vegetables (green leafy), and folic acid supplements reduce the risk of developing neural tube defects, such as spina bifida, and decrease the incidence of small-for-gestational-age newborns [55-57]. A moderate intake of fish, high adherence to the Mediterranean diet pattern, consumption of olive oil, and intake of specific vitamins (A, D, B1, B3, $\mathrm{B} 6, \mathrm{~B} 9$ and B12), and iron supplements reduce the risk of preterm delivery. It is debatable whether supplementation with n-3 LCPUFA during pregnancy or lactation can reduce allergic disease in children. Starch consumption has been differentially associated with childhood phenotypes, with a lower risk of wheezing, but a higher risk of eczema. High consumption of fish during pregnancy also seems to prevent the appearance of childhood eczema. Nut consumption during early pregnancy is associated with long-term childhood neuropsychological development. A maternal diet with significant consumption of pastries during pregnancy, consisting mainly of baked and sugary products, combined with a longer period of breastfeeding, can lead to the development of food allergies, suggesting a harmful effect of trans fat in the baby [58-68]. The maternal diet can even cushion the risk of other risk factors for neonatal pathology [63]. Another dietary pattern that has been fully addressed is maternal plant-based dietary intake. Vegetarian and vegan diets are becoming increasingly popular worldwide, especially among young adults. A recent prospective study carried out by Kesary et al. showed that a maternal vegan diet is a protective factor from excessive weight gain but associated with a higher risk for small-for-gestational-age newborn and lower birth weight centile [69], probably because vegans have been found to be at increased risk for deficiencies in vitamin levels, such as B12 and D, and in micronutrients, such as iron, zinc, iodine, and calcium that could increase this condition [70]. Regarding B12 vitamin, since there is no reliable plant-based food source for B12, several guidelines recommend that vegan women should receive adequate B12 supplementation and nutritional counseling [71]. Regarding vitamin D, and as pregnancy advances, the majority of women display a spontaneous reduction in circulating 25-hydroxyvitamin $\mathrm{D}(25(\mathrm{OH}) \mathrm{D})$ maternal levels' even 
in sunny regions [72]. Taking into account the relationship between vitamin D levels and newborn conditions, epidemiological nutritional studies support vitamin D supplementation during pregnancy to improve maternal, fetal, and immediate and later offspring health [73].

\section{Nutritional Recommendations for Pregnant Women by Health Professionals}

Advising pregnant women about the importance of having a healthy lifestyle that combines a healthy diet and regular physical activity during pregnancy to stay healthy and not excessively gain weight during pregnancy is recommended. It should be remembered that diet during pregnancy must be personalized and adapted to the energy and nutrient needs of each pregnant woman, assuming that these also change during the different trimesters of pregnancy and also after delivery [74].

In undernourished populations, it is necessary to provide nutritional information about the importance of increasing calorie and protein intake in pregnant women to reduce the risk of giving birth to low birthweight neonates.

A healthy diet during pregnancy contains an adequate amount of energy, protein, vitamins, and minerals obtained through the consumption of varied and healthy foods, including vegetables, meat, fish, legumes, nuts, whole grains and fruit [75].

Nutritional counseling and education are key strategies that are used frequently to improve the nutritional status of women during pregnancy. These strategies focus mainly on the following elements: Improving the quality of the maternal diet by increasing the diversity and the amount of healthy food consumed and promoting an adequate weight gain through sufficient and balanced protein and energy intake. Furthermore, it should be noted that the recommendations for healthy foods such as intake of nuts or consumption of fruits (three pieces daily) and vegetables are taken for granted in many cases and are not addressed in depth. Finally, it is necessary to restrict and avoid unhealthy foods such as sweets and processed food rich in saturated fatty acids. Vegan women need to receive adequate B12 supplementation and nutritional counseling.

Available data indicate that nutrition education and counseling can improve pregnancy weight gain, reduce the risk of anemia in late pregnancy, increase birth weight, and reduce the risk of preterm delivery. These interventions may be more effective when women are also given nutritional support, for example, in the form of food supplements or micronutrient supplements. The systematic intake of micronutrient, iron, and multivitamin supplements in all pregnant women is not recommended as it has not been found to be exempt of risks. This advice must be adapted to the real needs of each woman $[65,76,77]$. However, folic acid supplementation by all pregnant women from the preconception stage for preventing neural tube defects does have support, although it has also been associated with adverse effects during pregnancy [78,79].

The energy cost of an entire pregnancy is approximately 75,000 kcal. Recommendations range from $200 \mathrm{kcal}$ a day, recommended in only the third trimester by British institutions, to an extra $300 \mathrm{kcal}$ daily recommended throughout pregnancy by the WHO. In Spain, pregnant women are recommended to increase their daily intake by $250 \mathrm{kcal} /$ day during the second half of the pregnancy. Logically, these values vary depending on the previous weight of the pregnant woman. The sensible approach is to individualize each case according to BMI at the beginning of pregnancy and physical exercise, adapting the energy supply to the mother's weight gain, and avoiding ketosis.

The actual protein intake in the routine daily diet always exceeds the recommended intakes, which means that there are seldom problems of protein malnutrition, although the development of maternal and fetal tissues, a priori, would require an extra contribution.

During pregnancy, free fatty acids, triglycerides, total cholesterol, and phospholipids increase due to changes in liver and adipose tissue metabolism. These are also used for the formation of maternal and fetal tissues.

In terms of carbohydrates, it is advisable to distribute consumption throughout the day to avoid hypoglycemia. Foods must be rich in complex carbohydrates (starches and fiber) and less than $10 \%$ in the form of simple sugars [80]. 
It would also be advisable to make a series of recommendations regarding hygienic handling of food, precautions to be taken for some foods when cooking, reheating foods, etc. Advice should also include avoiding consuming certain foods during pregnancy such as swordfish, shark, bluefin tuna, raw milk, raw or undercooked meat, raw fish, pâtés sold refrigerated, and packaged sandwiches, etc. [81].

Some basic advice, in a language accessible to the entire population, that can be encouraged and remembered at each consultation is [18] as follows:

I. Eat in moderation and include a variety of foods with each meal.

II. Consume milk, yogurt, or cheese every day.

III. Eat fruits and vegetables of all kinds and colors daily.

IV. Eat a wide variety of red and white meats while removing visible fat.

V. Prepare meals with preferably raw vegetable oil and avoid cooking fat.

VI. Decrease the consumption of sugar and salt.

VII. Consume a wide variety of bread, cereals, pasta, flours, starches, and legumes.

VIII. Do not consume alcoholic beverages.

IX. Drink plenty of drinking water throughout the day.

X. Take advantage of mealtimes for getting together and chatting with others.

During pregnancy, a balanced and varied diet should be followed based on the recommendations of the nutritional pyramid with some adaptations such as the elimination of alcohol intake, although there are recent studies that associate very moderate alcohol consumption with lower indices of Small for Gestational Age (SGA) newborns [82]. Between four and five meals a day are recommended, with a full breakfast comprising the highest caloric intake of the day (made up of dairy products, fruits, and cereals), a not very abundant midday meal, a dinner a few hours before bedtime (being able to take a piece of fruit or dairy before bed), and avoid snacking between meals. Water consumption should be at least 2-2.5 L a day, and the consumption of foods rich in fats and sugars should be reduced, along with fried foods and salt [83]. Recent evidence, from vitamin D intervention studies and meta-analyses of a large number of studies, support vitamin D supplementation during pregnancy to improve maternal, fetal, and, immediate and long-term offspring health [73]. Informing mothers about all these nutritional aspects is essential to provide them with the education and information needed to make healthier decisions.

\section{Conclusions}

The maternal diet before and during pregnancy plays a fundamental role in the prevention of certain diseases in a child during early life and also at older ages. The maternal diet has a direct association with the appearance of diseases during pregnancy, and also has an indirect effect by playing an important role in the development of diseases during pregnancy that are associated with subsequent childhood diseases.

Author Contributions: J.M.M.-G. designed research; M.D.-R. and J.M.M.-G. conducted research; J.M.M.-G., M.D.-R. and N.C.-I. wrote the paper; J.M.M.-G. had primary responsibility for final content; A.H.-M. and N.C.-I. carried out a critical review of the article. All authors have read and agreed to the published version of the manuscript.

Funding: This research was funded by University of Jaen.

Conflicts of Interest: The authors declare no conflict of interest. The funders had no role in the design of the study; in the collection, analyses, or interpretation of data; in the writing of the manuscript, or in the decision to publish the results. 


\section{References}

1. Lugones Botell, M. Atención preconcepcional como estrategia básica para prevenir y disminuir la mortalidad materno-infantil. Rev. Cuba. Obs. Ginecol. 2016, 42, 1-3.

2. Bru Martín, C.; Martínez Galiano, J.M.; de Dios Berlanga, S. Mujeres que reciben asistencia preconcepcional en Granada. Matronas Prof. 2008, 9, 11-14.

3. Álvarez, E.; Moreno, M.; Valecillos, L.; Andrade, A.; Reyes, K.; García, J. GO-006: Complicaciones maternofetales relacionadas con Bajo Control Prenatal. Revisión de Historias Médicas del área de Alto Riesgo Obstétrico de la Maternidad Dr. Armando Castillo Plaza. Investig. Clínica 2017, 58, 494.

4. Villon, A.; Janet, N. Control Prenatal Inadecuado Como Factor de Riesgo para la Morbimortalidad Neonatal en un Hospital de Referencia de Lima Octubre-Diciembre 2018. 2019. Available online: http://repositorio. unfv.edu.pe/handle/UNFV/2918 (accessed on 10 June 2019).

5. Makate, M.; Makate, C. The impact of prenatal care quality on neonatal, infant and child mortality in Zimbabwe: Evidence from the demographic and health surveys. Health Policy Plan 2017, 32, 395-404. [CrossRef]

6. Yan, J. The Effects of Prenatal Care Utilization on Maternal Health and Health Behaviors. Health Econ. 2017, 26, 1001-1018. [CrossRef]

7. Fernández, Y.; Garcìa, G.; Estrada, A.; Kassandra, O. Inasistencia al control prenatal: ¿Cuáles son los principales factores asociados? Conoc. Desarro. 2019, 10, 9-16. [CrossRef]

8. Plata, M.; Jinary, A.; Rojas, J.; Paola, A.; Uribe, S.; Sofía, B. Factores Económicos, Socioculturales y Geográficos Que Influyen en la Adherencia al Control Prenatal en la Gestante de un Centro de Salud de Bucaramanga en el Primer Semestre de 2018. 2018. Available online: http://hdl.handle.net/20.500.12494/12671 (accessed on 25 September 2019).

9. Sánchez-Gómez, A.; Cevallos, W.; Grijalva, M.J.; Silva-Ayçaguer, L.C.; Tamayo, S.; Jacobson, J.O.; Costales, J.A.; Jiménez-García, R.; Hernández-Barrera, V.; Serruya S m Celia Riera, C. Factores sociales asociados con la utilización de los servicios de atención prenatal en Ecuador. Rev. Panam. Salud Publica 2016, 40, 341-346.

10. Sociedad Española de Ginecología y Obstetricia. Control prenatal del embarazo normal. Prog. Obstet. Ginecol. 2018, 61, 510-527.

11. Generalitat de Catalunya. Departament de Salut. Agència de Salut Pública de Catalunya. In Protocol de Seguiment de L'embaràs a Catalunya $3^{a}$ Edición Barcelona; Departament de Salut: Barcelona, Spain, 2018.

12. Consejería de Igualdad, Salud y Políticas Sociales de la Junta de Andalucía. Embarazo, Parto y Puerperio: Proceso Asistencial Integrado $3^{a}$ Ed; Consejería de Igualdad, Salud y Políticas Sociales: Sevilla, Spain, 2014.

13. Organización Mundial de la Salud. Recomendaciones de la OMS Sobre Atención Prenatal para una Experiencia Positiva del Embarazo; Organización Panamericana de la Salud: Washington, DC, USA, 2018.

14. Pajuelo Ramírez, J. Valoración del estado nutricional en la gestante. Rev. Peru. Ginecol. Obstet. 2014, 60, 147-152.

15. Organización Mundial de la Salud BMI Classification. 2019. Available online: http://apps.who.int/bmi/index. jsp?introPage=intro_3.html (accessed on 15 June 2019).

16. Mardones, S.F. Evolución de la antropometría materna y del peso de nacimiento en chile, 1987-2000. Rev. Chil. Nutr. 2003, 30, 122-131. [CrossRef]

17. Hernández Díaz, D.; Sarasa Muñoz, N.L.; Cañizares Luna, O.; Lima Pérez, Y.; Ruiz González, L.E.; Orozco Muñoz, C. Las Acciones Sistemáticas en Salud Mejoran el Control y Seguimiento Ponderal de las Embarazadas. ARS MEDICA Rev. Cienc. Méd. 2016, 40, 28-38.

18. Ministerio de Salud de la Nación. Nutrición Y Embarazo; Recomendaciones en Nutrición para los equipos de salud-Dirección Nacional de Maternidad e Infancia, Ministerio de Salud: Buenos Aires, Argentina, 2012.

19. Backes, C.H.; Markham, K.; Moorehead, P.; Cordero, L.; Nankervis, C.A.; Giannone, P.J. Maternal preeclampsia and neonatal outcomes. J. Pregnancy 2011, 214365. [CrossRef] [PubMed]

20. Bokslag, A.; van Weissenbruch, M.; Mol, B.W.; de Groot, C.J. Preeclampsia; short and long-term consequences for mother and neonate. Early Hum. Dev. 2016, 102, 47-50. [CrossRef] [PubMed]

21. Kaplan, O.; Wainstock, T.; Sheiner, E.; Staretz-Chacham, O.; Walfisch, A. Maternal anemia and offspring failure to thrive-results from a large population-based cohort. J. Matern Fetal Neonatal Med. 2019, 17, 1-7. [CrossRef] [PubMed] 
22. Lin, C.H.; Lin, W.D.; Chou, I.C.; Lee, I.C.; Hong, S.Y. Infants of Mothers With Diabetes and Subsequent Attention Deficit Hyperactivity Disorder: A Retrospective Cohort Study. Front. Pediatr. 2019, 7, 452. [CrossRef] [PubMed]

23. Lynch, T.A.; Malshe, A.; Colihan, S.; Meyers, J.; Li, D.; Holloman, C.; Soto-Torres, E.; Olson-Chen, C. Impact of Maternal Obesity on Perinatal Outcomes in Preterm Prelabor Rupture of Membranes $\geq 34$ Weeks. Am. J. Perinatol. 2019. [CrossRef]

24. Luisi, S.; Giorgi, M.; Riggi, S.; Messina, G.; Severi, F.M. Neonatal outcome in pregnancy hypotiroidee women. Gynecol Endocrinol. 2019, 23, 1-4. [CrossRef]

25. Smorti, M.; Ponti, L.; Tani, F. The effect of maternal depression and anxiety on labour and the well-being of the newborn. J. Obstet. Gynaecol. 2019, 39, 492-497. [CrossRef]

26. Ayensu, J.; Annan, R.; Lutterodt, H.; Edusei, A.; Peng, L.S. Prevalence of anaemia and low intake of dietary nutrients in pregnant women living in rural and urban areas in the Ashanti region of Ghana. PLoS ONE 2020, 15, e0226026. [CrossRef]

27. Chen, X.; Zhao, D.; Mao, X.; Xia, Y.; Baker, P.N.; Zhang, H. Maternal Dietary Patterns and Pregnancy Outcome. Nutrients 2016, 8, 351. [CrossRef]

28. Hutcheon, J.A.; Stephansson, O.; Cnattingius, S.; Bodnar, L.M.; Wikström, A.K.; Johansson, K. Pregnancy Weight Gain Before Diagnosis and Risk of Preeclampsia: A Population-Based Cohort Study in Nulliparous Women. Hypertension 2018, 72, 433-441. [CrossRef] [PubMed]

29. Mi, B.; Wen, X.; Li, S.; Liu, D.; Lei, F.; Liu, R.; Shen, Y.; Chen, Y.; Zeng, L.; Liu, X.; et al. Vegetable dietary pattern associated with low risk of preeclampsia possibly through reducing proteinuria. Pregnancy Hypertens. 2019, 16, 131-138. [CrossRef] [PubMed]

30. Shin, D.; Lee, K.W.; Song, W.O. Dietary Patterns during Pregnancy Are Associated with Risk of Gestational Diabetes Mellitus. Nutrients 2015, 7, 9369-9382. [CrossRef] [PubMed]

31. Gondwe, T.; Betha, K.; Kusneniwar, G.N.; Bunker, C.H.; Tang, G.; Simhan, H.; Reddy, P.S.; Haggerty, C.L. Maternal Factors Associated with Mode of Delivery in a Population with a High Cesarean Section Rate. J. Epidemiol. Glob. Health 2019, 9, 252-258. [CrossRef] [PubMed]

32. Chisholm, K.M.; Folkins, A.K. Placental and Clinical Characteristics of Term Small-for-Gestational-Age Neonates: A Case-Control Study. Pediatr. Dev. Pathol. 2016, 19, 37-46. [CrossRef]

33. Vik, T.; Redline, R.; Nelson, K.B.; Bjellmo, S.; Vogt, C.; Ng, P.; Strand, K.M.; Nu, T.N.T.; Oskoui, M. The Placenta in Neonatal Encephalopathy: A Case-Control Study. J. Pediatr. 2018, 202, 77-85.e3. [CrossRef]

34. Krzeczkowski, J.E.; Boylan, K.; Arbuckle, T.E.; Muckle Poliakova, N.; Séguin, J.R.; Favotto, L.A.; Savoy, C.; Amani, B.; Mortaji, N.; Van Lieshout, R.J. Maternal Pregnancy Diet Quality Is Directly Associated with Autonomic Nervous System Function in 6-Month-Old Offspring. J. Nutr. 2020, 150, 267-275. [CrossRef]

35. Catalano, P.M.; Shankar, K. Obesity and pregnancy: Mechanisms of short term and long term adverse consequences for mother and child. BMJ 2017, 356, j1. [CrossRef]

36. Contu, L.; Hawkes, C.A. A Review of the Impact of Maternal Obesity on the Cognitive Function and Mental Health of the Offspring. Int. J. Mol. Sci. 2017, 18, 1093. [CrossRef]

37. Edlow, A.G. Maternal obesity and neurodevelopmental and psychiatric disorders in offspring. Prenat. Diagn. 2017, 37, 95-110. [CrossRef]

38. Kong, L.; Nilsson, I.A.K.; Brismar, K.; Gissler, M.; Lavebratt, C. Associations of Different Types of Maternal Diabetes and Body Mass Index with Offspring Psychiatric Disorders. JAMA Netw. Open 2020, 3, e1920787. [CrossRef] [PubMed]

39. Mat Husin, H.; Schleger, F.; Bauer, I.; Fehlert, E.; Kiefer-Schmidt, I.; Weiss, M.; Kagan, K.O.; Brucker, S.; Pauluschke-Fröhlich, J.; Eswaran, H.; et al. Maternal Weight, Weight Gain, and Metabolism are Associated with Changes in Fetal Heart Rate and Variability. Obesity 2020, 28, 114-121. [CrossRef] [PubMed]

40. Pullar, J.; Wickramasinghe, K.; Demaio, A.R.; Roberts, N.; Perez-Blanco, K.M.; Noonan, K.; Townsend, N. The impact of maternal nutrition on offspring's risk of non-communicable diseases in adulthood: A systematic review. J. Glob. Health 2019, 9, 020405. [CrossRef] [PubMed]

41. Sanchez, C.E.; Barry, C.; Sabhlok, A.; Russell, K.; Majors, A.; Kollins, S.H.; Fuemmeler, B.F. Maternal pre-pregnancy obesity and child neurodevelopmental outcomes: A meta-analysis. Obes. Rev. 2018, 19, 464-484., PMID: 29164765; PMCID: PMC6059608. [CrossRef] 
42. Tam, C.H.T.; Ma, R.C.W.; Yuen, L.Y.; Ozaki, R.; Li, A.M.; Hou, Y.; Chan, M.H.M.; Ho, C.S.; Yang, X.; Chan, J.C.N.; et al. The impact of maternal gestational weight gain on cardiometabolic risk factors in children. Diabetologia 2018, 61, 2539-2548. [CrossRef]

43. Ukah, U.V.; Bayrampour, H.; Sabr, Y.; Razaz, N.; Chan, W.S.; Lim, K.I.; Lisonkova, S. Association between gestational weight gain and severe adverse birth outcomes in Washington State, US: A population-based retrospective cohort study, 2004-2013. PLoS Med. 2019, 16, e1003009. [CrossRef]

44. Kozuki, N.; Katz, J.; Christian, P.; Lee, A.C.C.; Li Liu Silveira, M.F.; Barros, F.; Tielsch, J.M.; Schmiegelow, C.; Sania, A.; Roberfroid, D.; et al. Comparison of US Birth Weight References and the International Fetal and Newborn Growth Consortium for the 21st Century Standard. JAMA Pediatr. 2015, 169, e151438. [CrossRef]

45. Muhihi, A.; Sudfeld, C.R.; Smith, E.R.; Noor, R.A.; Mshamu, S.; Briegleb, C.; Bakari, M.; Masanja, H.; Fawzi, W.; Chan, G.J. Risk factors for small-for-gestational-age and preterm births among 19,269 Tanzanian newborns. BMC Pregnancy Childbirth 2016, 16, 110, PMID: 27183837; PMCID: PMC4869183. [CrossRef]

46. Premru-Srsen, T.; Verdenik, I.; Ponikvar, B.M.; Steblovnik, L.; Geršak, K.; Cerar, L.K. Infant mortality and causes of death by birth weight for gestational age in non-malformed singleton infants: A 2002-2012 population-based study. J. Perinat. Med. 2018, 46, 547-553. [CrossRef]

47. Sania, A.; Smith, E.R.; Manji, K.; Duggan, C.; Masanja, H.; Kisenge, R.; Msamanga, G.; Urassa, W.; Fawzi, W. Neonatal and Infant Mortality Risk Associated with Preterm and Small for Gestational Age Births in Tanzania: Individual Level Pooled Analysis Using the Intergrowth Standard. J. Pediatr. 2018, 192, 66-72.e4. [CrossRef]

48. El Rafei, R.; Abbas, H.A.; Charafeddine, L.; Nakad, P.; Al Bizri, A.; Hamod, D.; Yunis, K.A. Association of Pre-Pregnancy Body Mass Index and Gestational Weight Gain with Preterm Births and Fetal Size: An Observational Study from Lebanon. Paediatr. Perinat. Epidemiol. 2016, 30, 38-45. [CrossRef]

49. Goldstein, R.F.; Abell, S.K.; Ranasinha, S.; Misso, M.; Boyle, J.A.; Black, M.H.; Li, N.; Hu, G.; Corrado, F.; Rode, L.; et al. Association of Gestational Weight Gain With Maternal and Infant Outcomes: A Systematic Review and Meta-analysis. JAMA 2017, 317, 2207-2225. [CrossRef] [PubMed]

50. Pigatti Silva, F.; Souza, R.T.; Cecatti, J.G.; Passini, R., Jr.; Tedesco, R.P.; Lajos, G.J.; Nomura, M.L.; Rehder, P.M.; Dias, T.Z.; Oliveira, P.F.; et al. Brazilian Multicenter Study on Preterm Birth (EMIP) study group. Role of Body Mass Index and gestational weight gain on preterm birth and adverse perinatal outcomes. Sci. Rep. 2019, 9, 1-12. [CrossRef] [PubMed]

51. Slack, E.; Best, K.E.; Rankin, J.; Heslehurst, N. Maternal obesity classes, preterm and post-term birth: A retrospective analysis of 479,864 births in England. BMC Pregnancy Childbirth 2019, 19, 434. [CrossRef]

52. Yee, L.M.; Silver, R.M.; Haas, D.M.; Parry, S.; Mercer, B.M.; Iams, J.; Wing, D.; Parker, C.B.; Reddy, U.M.; Wapner, R.J.; et al. Quality of periconceptional dietary intake and maternal and neonatal outcomes. Am. J. Obstet. Gynecol. 2020, 223, 121.e1-121.e8. [CrossRef] [PubMed]

53. Alves-Santos, N.H.; Cocate, P.G.; Benaim, C.; Farias, D.R.; Emmett, P.M.; Kac, G. Prepregnancy Dietary Patterns and Their Association with Perinatal Outcomes: A Prospective Cohort Study. J. Acad. Nutr. Diet. 2019, 119, 1439-1451. [CrossRef]

54. Cano-Ibáñez, N.; Martínez-Galiano, J.M.; Amezcua-Prieto, C.; Olmedo-Requena, R.; Bueno-Cavanillas, A.; Delgado-Rodríguez, M. Maternal dietary diversity and risk of small for gestational age newborn: Findings from a case-control study. Clin. Nutr. 2020, 39, 1943-1950. [CrossRef]

55. Martínez-Galiano, J.M.; Amezcua-Prieto, C.; Salcedo-Bellido, I.; González-Mata, G.; Bueno-Cavanillas, A.; Delgado-Rodríguez, M. Maternal dietary consumption of legumes, vegetables and fruit during pregnancy, does it protect against small for gestational age? BMC Pregnancy Childbirth 2018, 2018. 18, 486. [CrossRef]

56. Murphy, M.M.; Stettler, N.; Smith, K.M.; Reiss, R. Associations of consumption of fruits and vegetables during pregnancy with infant birth weight or small for gestational age births: A systematic review of the literature. Int. J. Women's Health 2014, 6, 899-912. [CrossRef]

57. Mousa, A.; Naqash, A.; Lim, S. Macronutrient and Micronutrient Intake during Pregnancy: An Overview of Recent Evidence. Nutrients 2019, 11, 443. [CrossRef]

58. Amezcua-Prieto, C.; Martínez-Galiano, J.M.; Salcedo-Bellido, I.; Olmedo-Requena, R.; Bueno-Cavanillas, A.; Delgado-Rodríguez, M. Maternal seafood intake and the risk of small for gestational age newborns: A case-control study in Spanish women. BMJ Open 2018, 8, e020424. [CrossRef] [PubMed] 
59. Gignac, F.; Romaguera, D.; Fernández-Barrés, S.; Phillipat, C.; Esteban, R.G.; López-Vicente, M.; Vioque, J.; Fernández-Somoano, A.; Tardón, A.; Iñiguez, C.; et al. Maternal nut intake in pregnancy and child neuropsychological development up to 8 years old: A population-based cohort study in Spain. Eur. J. Epidemiol. 2019, 34, 661-673. [CrossRef] [PubMed]

60. Grieger, J.A.; Pelecanos, A.M.; Hurst, C.; Tai, A.; Clifton, V.L. Pre-Conception Maternal Food Intake and the Association with Childhood Allergies. Nutrients 2019, 11, 1851. [CrossRef] [PubMed]

61. Gunaratne, A.W.; Makrides, M.; Collins, C.T. Maternal prenatal and/or postnatal n-3 long chain polyunsaturated fatty acids (LCPUFA) supplementation for preventing allergies in early childhood. Cochrane Database Syst. Rev. 2015, 7, CD010085. [CrossRef]

62. Kim, Y.H.; Kim, K.W.; Lee, S.Y.; Koo, K.O.; Kwon, S.O.; Seo, J.H.; Suh, D.I.; Shin, Y.H.; Ahn, K.; Oh, S.Y.; et al. Maternal Perinatal Dietary Patterns Affect Food Allergy Development in Susceptible Infants. J. Allergy Clin. Immunol. Pract. 2019, 7, 2237-2347.e7. [CrossRef]

63. Martínez-Galiano, J.M.; Amezcua-Prieto, C.; Cano-Ibañez, N.; Olmedo-Requena, R.; Jiménez-Moleón, J.J.; Bueno-Cavanillas, A.; Delgado-Rodríguez, M. Diet as a counteracting agent of the effect of some well-known risk factors for small for gestational age. Nutrition 2020, 72, 110665. [CrossRef]

64. Martínez-Galiano, J.M.; Olmedo-Requena, R.; Barrios-Rodríguez, R.; Amezcua-Prieto, C.; Bueno-Cavanillas, A.; Salcedo-Bellido, I.; Jimenez-Moleon, J.J.; Delgado-Rodríguez, M. Effect of Adherence to a Mediterranean Diet and Olive Oil Intake during Pregnancy on Risk of Small for Gestational Age Infants. Nutrients 2018, 10, 1234. [CrossRef]

65. Martínez-Galiano, J.M.; Amezcua-Prieto, C.; Cano-Ibañez, N.; Salcedo-Bellido, I.; Bueno-Cavanillas, A.; Delgado-Rodriguez, M. Maternal iron intake during pregnancy and the risk of small for gestational age. Matern. Child Nutr. 2019, 15, e12814. [CrossRef]

66. Miyake, Y.; Tanaka, K.; Okubo, H.; Sasaki, S.; Arakawa, M. Maternal fat intake during pregnancy and wheeze and eczema in Japanese infants: The Kyushu Okinawa Maternal and Child Health Study. Ann Epidemiol. 2019, 674-680. [CrossRef]

67. Pretorius, R.A.; Bodinier, M.; Prescott, S.L.; Palmer, D.J. Maternal Fiber Dietary Intakes during Pregnancy and Infant Allergic Disease. Nutrients 2019, 11, 1767. [CrossRef]

68. Salcedo-Bellido, I.; Martínez-Galiano, J.M.; Olmedo-Requena, R.; Mozas-Moreno, J.; Bueno-Cavanillas, A.; Jimenez-Moleon, J.J.; Delgado-Rodríguez, M. Association between Vitamin Intake during Pregnancy and Risk of Small for Gestational Age. Nutrients 2017, 9, 1277. [CrossRef] [PubMed]

69. Kesary, Y.; Avital, K.; Hiersch, L. Maternal plant-based diet during gestation and pregnancy outcomes. Arch. Gynecol. Obstet. 2020, 302, 887-898. [CrossRef] [PubMed]

70. Avnon, T.; Anbar, R.; Lavie, I.; Ben-Mayor Bashi, T.; Paz Dubinsky, E.; Shaham, S.; Yogev, Y. Does vegan diet influence umbilical cord vitamin B12, folate, and ferritin levels? Arch. Gynecol. Obstet. 2020, 301, 1417-1422. [CrossRef] [PubMed]

71. Baroni, L.; Goggi, S.; Battaglino, R.; Berveglieri, M.; Fasan, I.; Filippin, D.; Griffith, P.; Rizzo, G.; Tomasini, C.; Tosatti, M.A.; et al. Vegan nutrition for mothers and children: Practical tools for healthcare providers. Nutrients 2019, 11, 5. [CrossRef]

72. Fernández-Alonso, A.M.; Dionis-Sánchez, E.C.; Chedraui, P.; González-Salmerón, M.D.; Pérez-López, F.R. Spanish Vitamin D and Women's Health Research Group. First-trimester maternal serum 25-hydroxyvitamin $\mathrm{D}_{3}$ status and pregnancy outcome. Int. J. Gynaecol. Obstet. 2012, 116, 6-9. [CrossRef] [PubMed]

73. Pérez-López, F.R.; Pilz, S.; Chedraui, P. Vitamin D supplementation during pregnancy: An overview. Curr. Opin. Obstet. Gynecol. 2020, 32, 316-321. [CrossRef]

74. Beluska-Turkan, K.; Korczak, R.; Hartell, B.; Moskal, K.; Maukonen, J.; Alexander, D.E.; Salem, N.; Harkness, L.; Ayad, W.; Szaro, J.; et al. Nutritional Gaps and Supplementation in the First 1000 Days. Nutrients 2019, 11, 2891. [CrossRef]

75. Organización Mundial de la Salud. Asesoramiento Nutricional Durante el Embarazo. 2019. Available online: https://www.who.int/elena/titles/nutrition_counselling_pregnancy/es/ (accessed on 25 September 2019).

76. Harding, K.B.; Peña-Rosas, J.P.; Webster, A.C.; Yap, C.M.; Payne, B.A.; Ota, E.; De-Regil, L.M. Iodine supplementation for women during the preconception, pregnancy and postpartum period. Cochrane Database Syst. Rev. 2017, 3, CD011761. [CrossRef] 
77. Oh, C.; Keats, E.C.; Bhutta, Z.A. Vitamin and Mineral Supplementation during Pregnancy on Maternal, Birth, Child Health and Development Outcomes in Low-and Middle-Income Countries: A Systematic Review and Meta-Analysis. Nutrients 2020, 12, 491. [CrossRef]

78. Cheng, G.; Sha, T.; Gao, X.; He, Q.; Wu, X.; Tian, Q.; Yang, F.; Tang, C.; Wu, X.; Xie, Q.; et al. The Associations between the Duration of Folic Acid Supplementation, Gestational Diabetes Mellitus, and Adverse Birth Outcomes based on a Birth Cohort. Int. J. Environ. Res. Public Health 2019, 16, 4511. [CrossRef]

79. Haider, B.A.; Bhutta, Z.A. Multiple-micronutrient supplementation for women during pregnancy. Cochrane Database Syst. Rev. 2017, 4, CD004905. [CrossRef] [PubMed]

80. Cereceda Bujaico, M.P.; Quintana Salinas, M.R. Consideraciones para una adecuada alimentación durante el embarazo. Rev. Peru. Ginecol. Obstet. 2014, 60, 153-160.

81. Ministerio de Sanidad. Recomendaciones de Nutrición de la Sociedad Española de Endocrinología y Nutrición en el Embarazo. 2012. Available online: https:/www.mscbs.gob.es/ciudadanos/proteccionSalud/ mujeres/recomendaciones/recEmbarazo.htm (accessed on 25 September 2019).

82. Martínez-Galiano, J.M.; Amezcua-Prieto, C.; Salcedo-Bellido, I.; Olmedo-Requena, R.; Bueno-Cavanillas, A.; Delgado-Rodriguez, M. Alcohol consumption during pregnancy and risk of small-for-gestational-age newborn. Women Birth. 2019, 32, 284-288. [CrossRef] [PubMed]

83. Gonzalez Ballano, I. Aumento Ponderal Materno en la Gestación y Su Influencia en Los Resultados Perinatales. Ph.D. Thesis, Universidad de Zaragoza, Zaragoza, Spain, 2017.

Publisher's Note: MDPI stays neutral with regard to jurisdictional claims in published maps and institutional affiliations.

(C) 2020 by the authors. Licensee MDPI, Basel, Switzerland. This article is an open access article distributed under the terms and conditions of the Creative Commons Attribution (CC BY) license (http://creativecommons.org/licenses/by/4.0/). 